\title{
STUDY OF HISTOPATHOLOGICAL CHANGES OF GALLBLADDER IN CHOLELITHIASIS AND ITS CLINICAL RELEVANCE
}

\author{
Gyanaranjan Nayak', Saurjya Ranjan Das², Biswa Bhusan Mohanty33, Pratima Baisakh ${ }^{4}$, Sitansu Kumar Panda ${ }^{5}$, \\ Prafulla Kumar Chinara6
}

\begin{abstract}
${ }^{1}$ Assistant Professor, Department of Anatomy, IMS and SUM Hospital, SOA University, Bhubaneswar, Odisha, India. ${ }^{2}$ Assistant Professor, Department of Anatomy, IMS and SUM Hospital, SOA University, Bhubaneswar, Odisha, India. ${ }^{3}$ Associate Professor, Department of Anatomy, IMS and SUM Hospital, SOA University, Bhubaneswar, Odisha, India. ${ }^{4}$ Assistant Professor, Department of Anatomy, IMS and SUM Hospital, SOA University, Bhubaneswar, Odisha, India. ${ }_{5}^{5}$ Associate Professor, Department of Anatomy, IMS and SUM Hospital, SOA University, Bhubaneswar, Odisha, India. ${ }_{6}^{6}$ Professor, Department of Anatomy, IMS and SUM Hospital, SOA University, Bhubaneswar, Odisha, India.
\end{abstract}

\section{ABSTRACT}

Cholelithiasis as a disease is as old as the civilisation itself. And there is increased incidence of gallstone disease these days in India as well as the west. The disease has variable clinical presentation and a spectrum of histopathological changes associated with it.

\section{AIM OF THE STUDY}

To study the histopathological changes of gallbladder associated with cholelithiasis and correlate the findings clinically.

\section{MATERIALS AND METHODS}

Gallbladder specimens were collected from 70 surgery indoor admitted patients of cholelithiasis undergoing elective cholecystectomy. Resected specimens were fixed and detailed gross examination done. Several sections were obtained from fundus, body and neck of the gallbladders as well as from pathological abnormal sites. Sections obtai ned were stained with haematoxylin and eosin and subjected to light microscopy.

\section{RESULTS}

Most of the cases showed chronic cholecystitis and its variants followed by acute cholecystitis. Malignant and pre-malignant changes were also observed.

\section{CONCLUSION}

Detection of malignant and premalignant changes in the background of cholelithiasis makes the histopathological examination of gallbladder harbouring gallstones a necessity. And these changes also warrant cholecystectomy as the preferred treatment modality of cholelithiasis.

\section{KEYWORDS}

Gallbladder, Cholelithiasis, Cholecystectomy, Histopathology, Adenocarcinoma.

HOW TO CITE THIS ARTICLE: Nayak G, Das SR, Mohanty BB, et al. Study of histopathological changes of gallbladder in cholelithiasis and its clinical relevance. J. Evolution Med. Dent. Sci. 2016;5(45):2820-2824, DOI: 10.14260/jemds/2016/659

\section{INTRODUCTION}

Gallstones have been discovered in mummies preserved since early Egyptian civilization. In India, the description of gallbladder disease and jaundice is available in Rig Veda (5000-2000 BC), Mahabharat (1000 BC), Manu Samhita (1000 $\mathrm{BC}$ ) and Nagarjuna's literature. So cholelithiasis as a disease is known since antiquity.

The prevalence of gallstones is around 4\% in India and $10 \%$ in the western world.[1] An epidemiological study restricted to rail road workers showed that North Indians have seven times higher incidence of gallstones as compared to South Indians. [2] There has been a marked rise in the incidence of gallstones in the west during the past century. In the United States, the third National Health and Nutrition

Financial or Other, Competing Interest: None.

Submission 21-04-2016, Peer Review 15-05-2016,

Acceptance 21-05-2016, Published 06-06-2016.

Corresponding Author:

Dr. Gyanaranjan Nayak,

Flat No. 111, Manorama-Metro Complex,

Malasahi, Mangalabag

Cuttack-753001,

Odisha, India.

E-mail:drgrn82@gmail.com

DOI: $10.14260 /$ jemds $/ 2016 / 659$
Examination Survey (NHANES III) has revealed an overall prevalence of gallstones of $7.9 \%$ in men and $16.6 \%$ in women. [3] Prevalence is high in Mexican Americans (8.9\% in males, $26.7 \%$ in females); intermediate in non-Hispanic whites (8.6\% in males, $16.6 \%$ in females); low in African Americans (5.3\% in males and $13.9 \%$ in females).

In medical practice gallstones may present as emergency in a patient suddenly developing right upper abdominal pain, fever and chills with jaundice, whereas in asymptomatic patients gallstones may be an incidental finding to the radiologist. Cholelithiasis may present with the dreaded carcinoma of gallbladder.

According to Sternberg.[4] on histopathological examination, the gallbladder specimens resected for cholelithiasis present a number of pathological conditions like.

a. Cholesterolosis.

b. Hydrops and mucocoele.

c. Acute cholecystitis.

d. Chronic cholecystitis.

e. Variants of chronic cholecystitis - Follicular cholecystitis, Eosinophilic cholecystitis, Xanthogranulomatous cholecystitis.

f. Non-neoplastic epithelial alterations-hyperplasia, metaplasia. 
g. Non-neoplastic tumour like lesions - polyps, cysts.

h. Neoplasia of gallbladder.

As cholelithiasis and its variable clinical presentation are common in India as well as the west and gallbladder harbouring stones present various histopathological phenomena, the current study was carried out to detect the histological alterations of gallbladder in cholelithiasis and any premalignant and malignant conditions if associated with gallstones.

\section{MATERIALS AND METHODS}

Gallbladder specimens were collected from 70 surgery indoor admitted patients ( 49 females and 21 males) of cholelithiasis undergoing elective cholecystectomy. The procedure of collection of gallbladder specimens was according to the ethical standards of the Institutional Ethics Committee. For microscopy specimens were obtained from fundus, body and neck as well as from pathological abnormal sites of the resected gallbladder specimens. Tissues about $5 \mathrm{~mm}$ thick were fixed in $10 \%$ formalin. Then dehydration was done in a series of graduated changes of different strengths of ascending grades of alcohol $(30 \%, 50 \%, 70 \%, 80 \%$ and absolute alcohol) for approximately one hour each. Dehydrated specimens were cleared with xylol. After clearing, specimens were submerged in molten paraffin in paraffin bath. Two changes of paraffin each 1.5 hours long were done for proper infiltration. Embedding was done with L-shaped metals. Sectioning of the blocks was done with rotary microtome and sections of about 5-7 $\mu$ were obtained. The sections were stained with Haematoxylin and Eosin and subjected to light microscopy, magnification being 10X and 40X. Inference was drawn after consulting a pathologist.

\section{RESULTS}

Various histological alterations were observed and they were recorded under four headings - changes in epithelium, lamina propria, muscularis and subserosal connective tissue.

\section{The Changes were as follows}

A. Histological Alterations in Epithelium

1. Erosion of epithelium (Figure 1), feature of acute and chronic cholecystitis and adenocarcinoma.

2. Epithelial indipping into muscle layer (Figure 2), feature of chronic cholecystitis, adenomyoma and xanthogranulomatous cholecystitis.

3. Reactive atypia (Figure 3) consistent with acute cholecystitis.

4. Resemblance to gastric surface epithelium consistent with gastric surface metaplasia.

5. Goblet cells in epithelium or intestinal metaplasia (Figure 4) associated with chronic cholecystitis and adenocarcinoma.

6. Hyperchromatic accentuated fold or hyperplasia (Figure 5).

7. Disordered intraepithelial proliferation or dysplasia (Figure 6).

\section{B. Histological Alterations in Lamina Propria}

1. Inflammatory infiltrate (Figure 7) found in cholecystitis.
2. Fibrosis (Figure 8) which is consistent with acute and chronic cholecystitis, scleroatrophic gallbladder and xanthogranulomatous cholecystitis.

3. Foamy macrophages observed in cholesterolosis (Figure 9).

4. Oedema (Figure 8), which is observed in acute cholecystitis.

5. Haemorrhage (Figure 10), which is a result of inflammatory injury.

6. Pyloric type mucous glands were observed, which is called pyloric metaplasia (Figure 11) associated with chronic cholecystitis.

7. Well-formed glands with nuclear atypia, which is a feature of adenocarcinoma (Figure 12,13).

\section{Histological Alterations in Muscularis}

1. Fibrosis observed in cholecystitis and scleroatrophic gallbladder.

2. Inflammatory infiltrate observed in cholecystitis.

3. Muscle hypertrophy (Figure 14), which is consistent with chronic cholecystitis and adenomyomatosis.

4. Oedema which is observed in acute cholecystitis.

5. Haemorrhage which results from inflammatory damage to blood vessels.

\section{Histological Alterations in Subserosal Connective} Tissue

1. Inflammatory infiltrate found in cholecystitis.

2. Fibrosis consistent with acute as well as chronic cholecystitis.

3. Haemorrhage, result of inflammatory injury.

On summing up the above histological alterations, several histopathological conditions were observed which is summarised in Table 1.

In our study, most of the cases showed chronic cholecystitis and its variants followed by acute cholecystitis. Premalignant changes like metaplasia and dysplasia were also observed. One case was found to harbour adenocarcinoma.

\begin{tabular}{|c|c|c|c|c|}
\hline Sl. & $\begin{array}{c}\text { Histo- } \\
\text { pathological } \\
\text { Findings }\end{array}$ & $\begin{array}{c}\text { Incidence } \\
\text { (\%) in } \\
\text { Current } \\
\text { Series }\end{array}$ & $\begin{array}{c}\text { Ancidence } \\
\text { Adriana } \\
\text { Costa } \\
\text { Series }\end{array}$ & $\begin{array}{c}\text { Incidence } \\
\text { (\%) in } \\
\text { Almuslamani } \\
\text { Series }\end{array}$ \\
\hline 1 & $\begin{array}{c}\text { Chronic } \\
\text { cholecystitis }\end{array}$ & 62.8 & 64.5 & 60 \\
\hline 2 & Cholesterolosis & 14.2 & 18.1 & 18 \\
\hline 3 & Acute cholecystitis & 10 & 10.3 & 14 \\
\hline 4 & $\begin{array}{c}\text { Xanthogranulomatous } \\
\text { cholecystitis }\end{array}$ & 1.4 & 1.7 & 0.9 \\
\hline 5 & Hyperplasia & 1.4 & 0.2 & - \\
\hline 6 & Adenomyomatosis & 2.8 & 2.4 & 0.3 \\
\hline 7 & $\begin{array}{c}\text { Scleroatrophic } \\
\text { gallbladder }\end{array}$ & 1.4 & 1.2 & - \\
\hline 8 & $\begin{array}{c}\text { Metaplasia } \\
\text { (pyloric, gastric } \\
\text { surface, } \\
\text { intestinal type) }\end{array}$ & 5.7 & 5.3 & 1.8 \\
\hline 9 & Dysplasia & 1.4 & 0.2 & 1.5 \\
\hline 10 & Carcinoma & 1.4 & 0.1 & 0.5 \\
\hline \multicolumn{2}{|c|}{ Table 1: (Incidence of Histopathological Conditions in the } \\
Present Study and its Comparison \\
with other Workers)
\end{tabular}




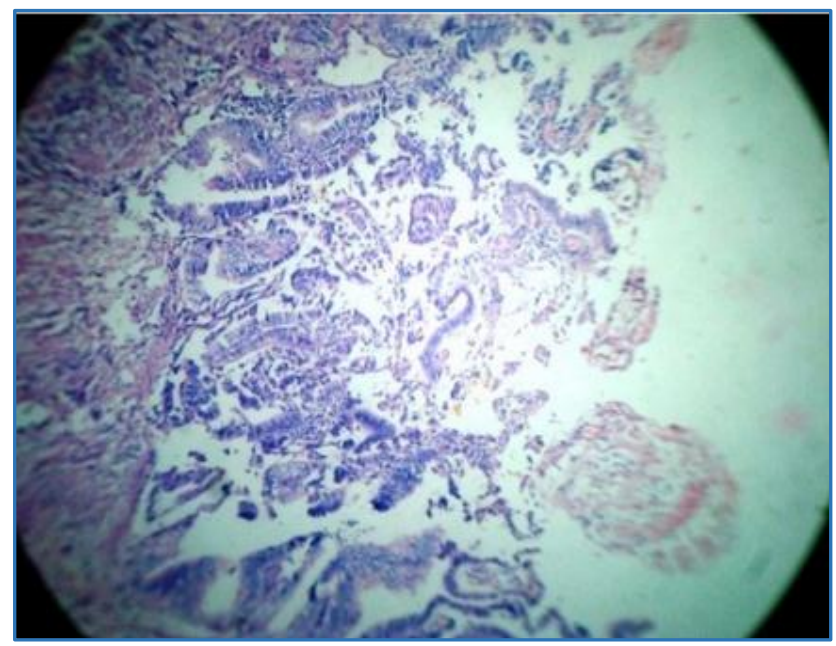

Fig. 1: Epithelial Erosion, $\mathrm{H}-\mathrm{Ex} 10$

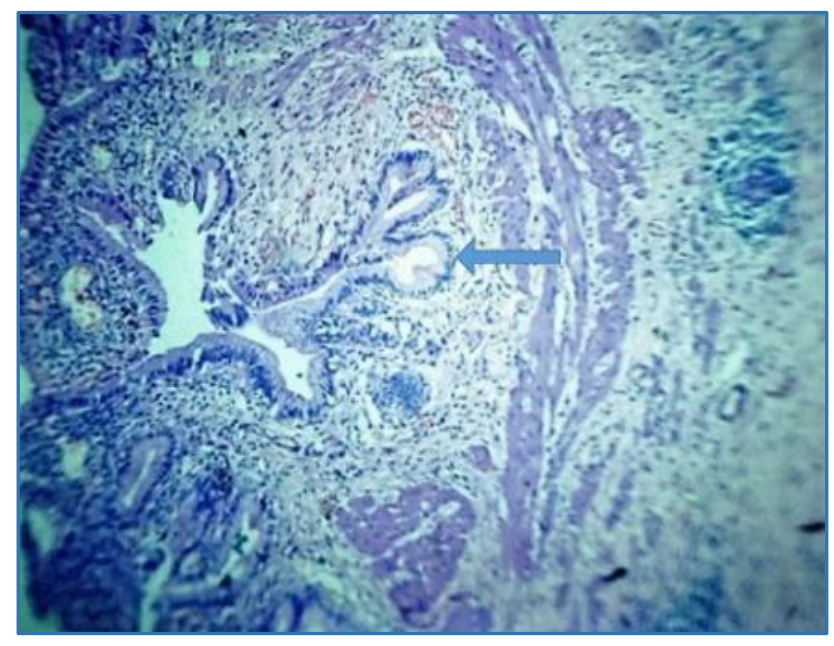

Fig. 2: Epithelial Indipping, H-Ex10

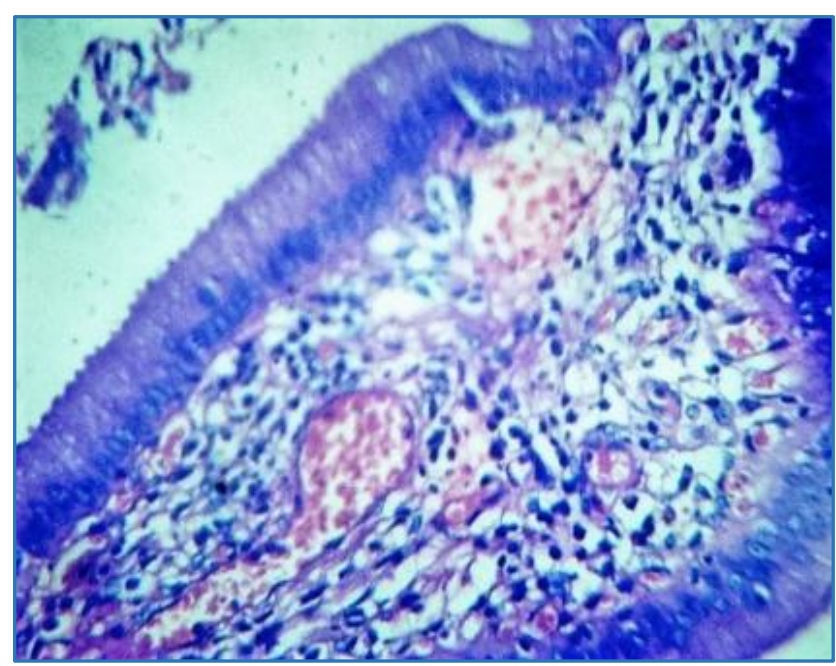

Fig. 3: Reactive Atypia of Epithelium, H-Ex40 (Nuclear Stratification without Disorganisation)

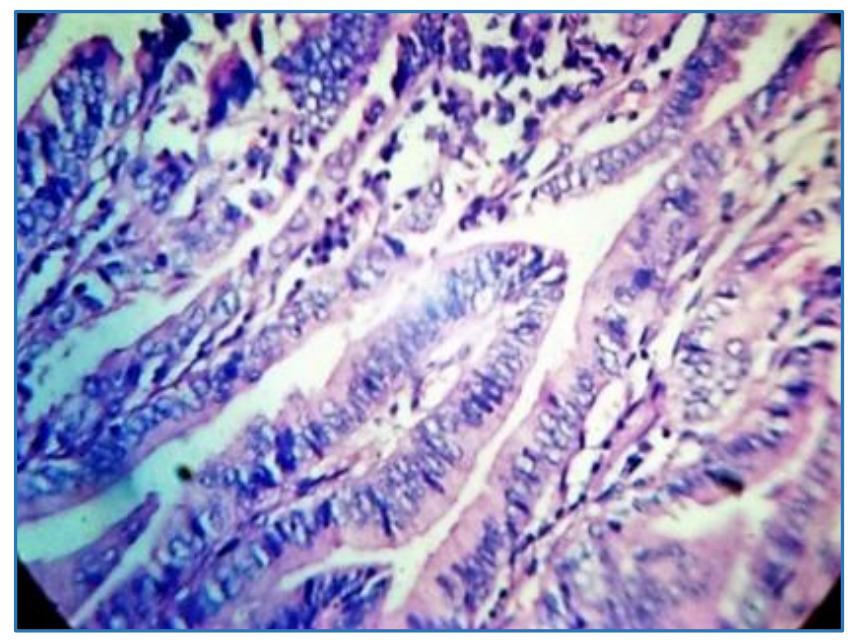

Fig. 4: Intestinal Metaplasia, H-Ex40 (Presence of Goblet Cells in Epithelium)

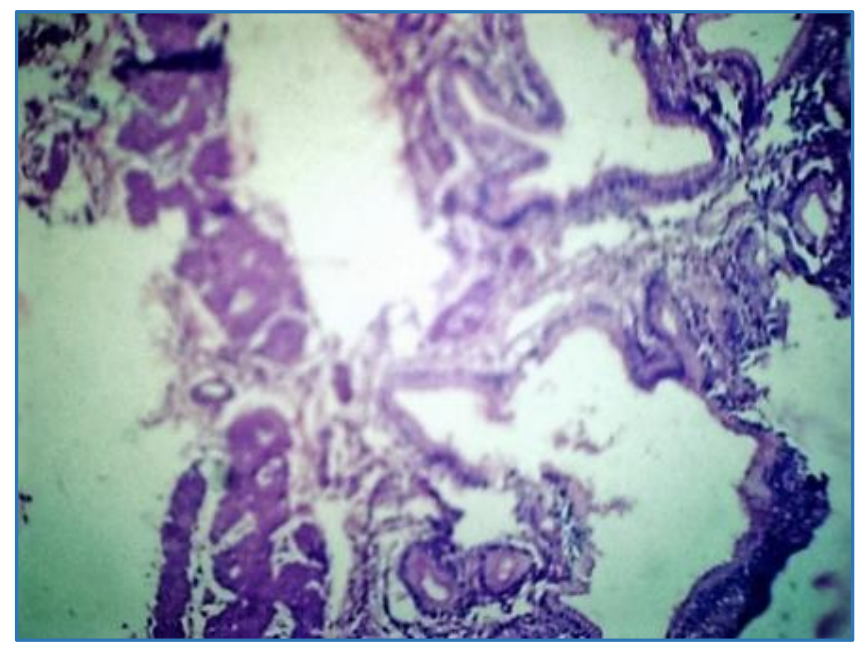

Fig. 5: Hyperplasia, $\mathrm{H}-\mathrm{Ex} 10$

(Hyperchromatic Accentuated Folds)

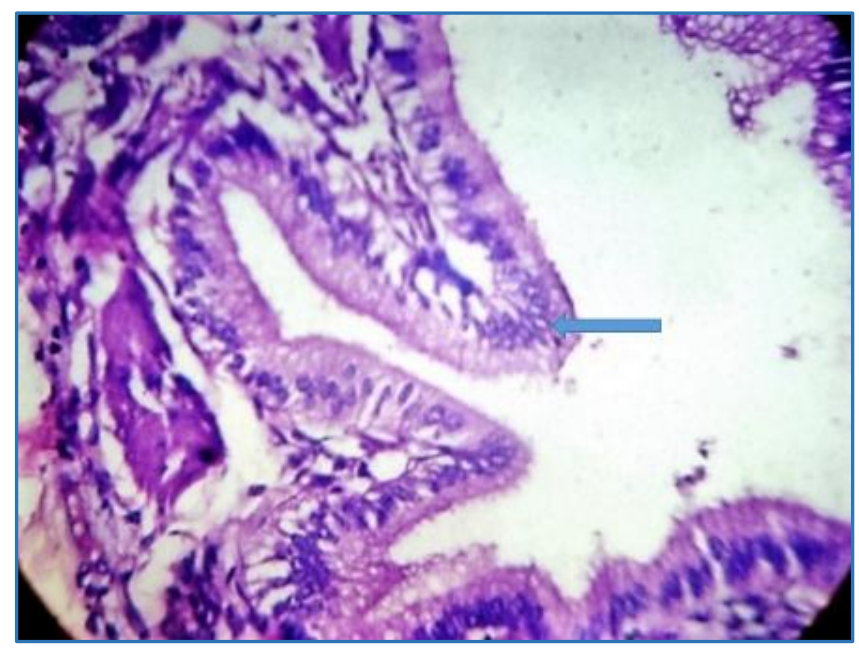

Fig. 6: Dysplasia, H-Ex40 (Disordered Intraepithelial Proliferation, that is Nuclear Stratification with Disorganisation) 


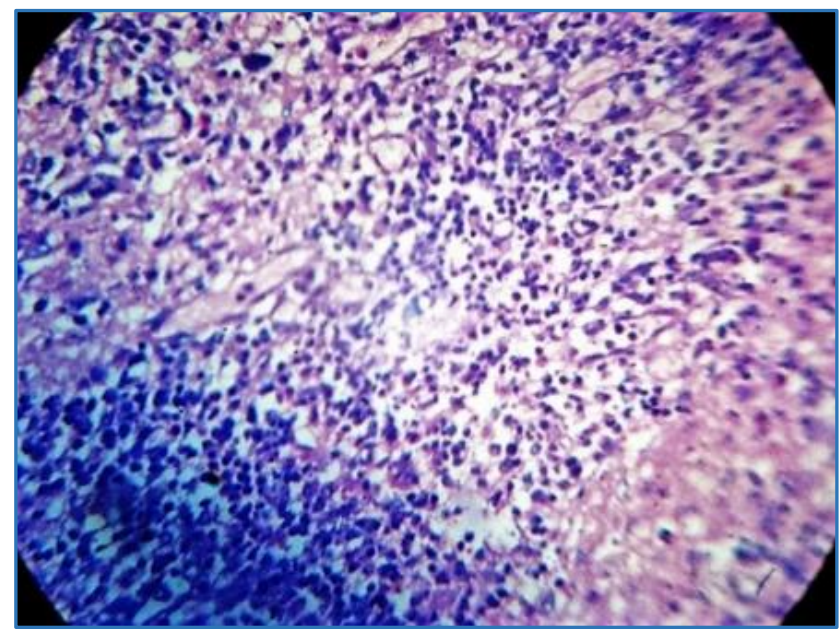

Fig. 7: Inflammatory Infiltrate, H-Ex40

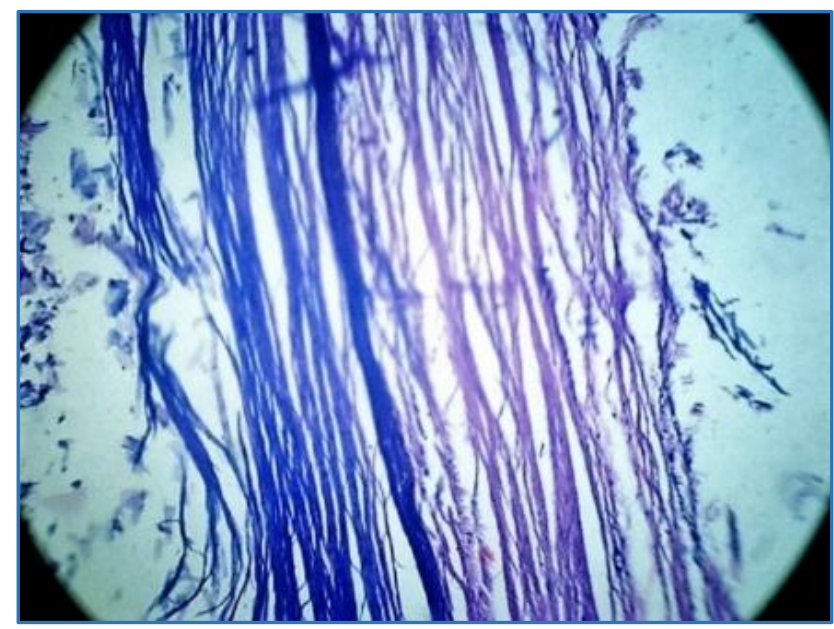

Fig. 8: Fibrosis with Oedema, H-Ex10

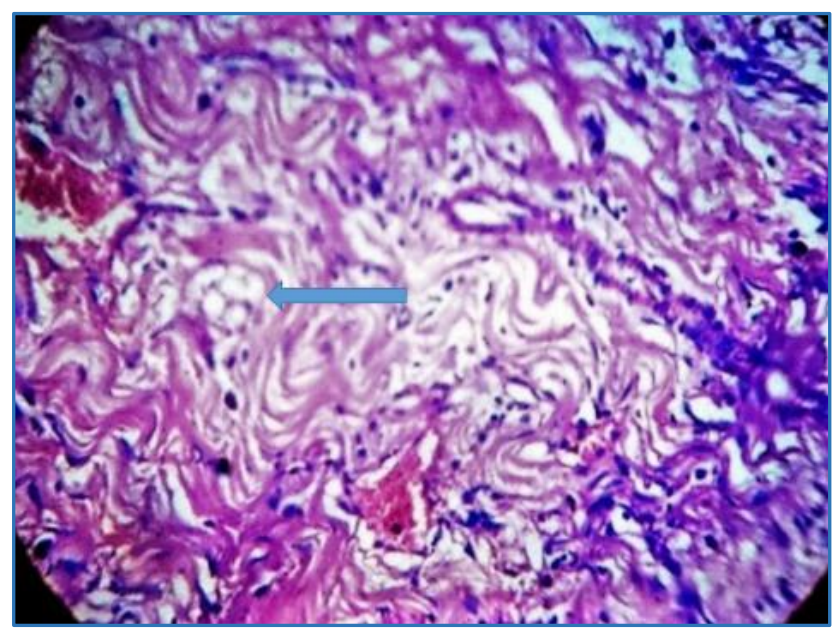

Fig. 9: Cholesterolosis, $\mathrm{H}-\mathrm{Ex} 40$ (Presence of Foamy Macrophages)

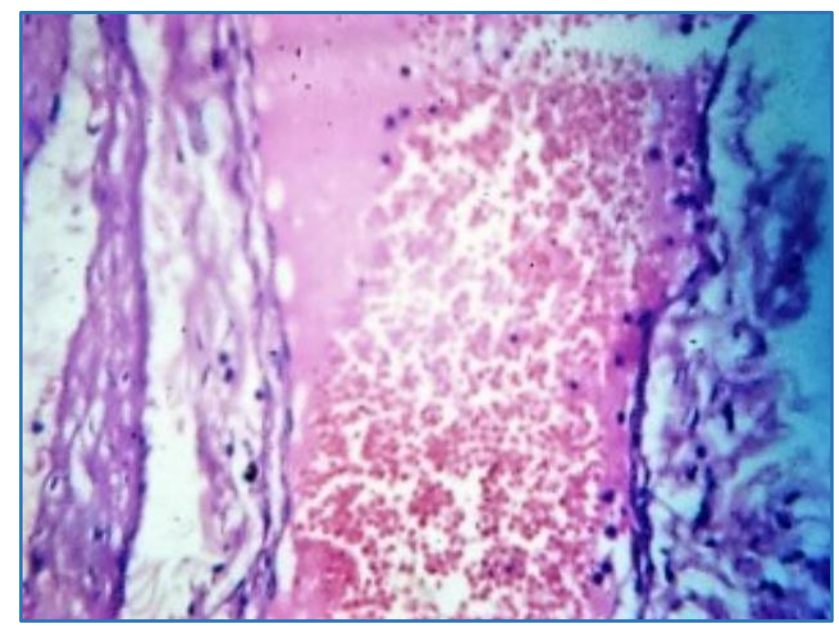

Fig. 10: Haemorrhage, H-Ex40

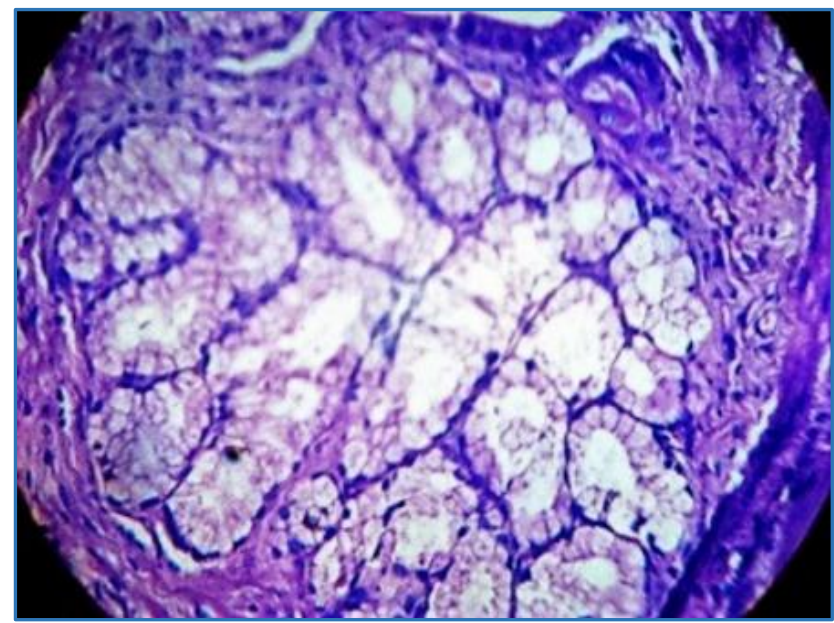

Fig. 11: Pyloric Metaplasia, H-Ex40 (Presence of Pyloric Type Mucous Glands in Lamina Propria)

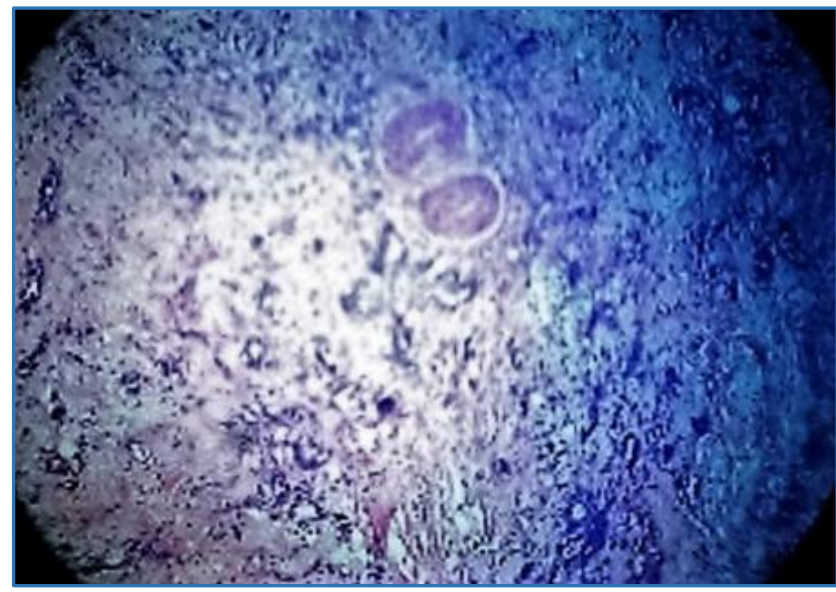

Fig. 12: Adenocarcinoma, H-Ex10 (Well-Formed Glands with Nuclear Atypia in Desmoplastic Stroma) 


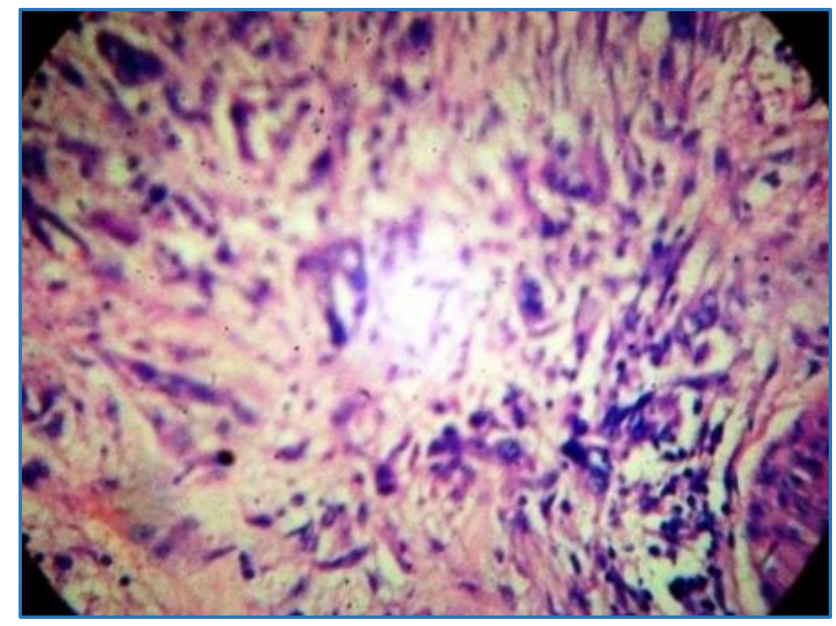

Fig. 13: Adenocarcinoma, H-Ex40 (Well-Formed Glands with Nuclear Atypia in Desmoplastic Stroma)

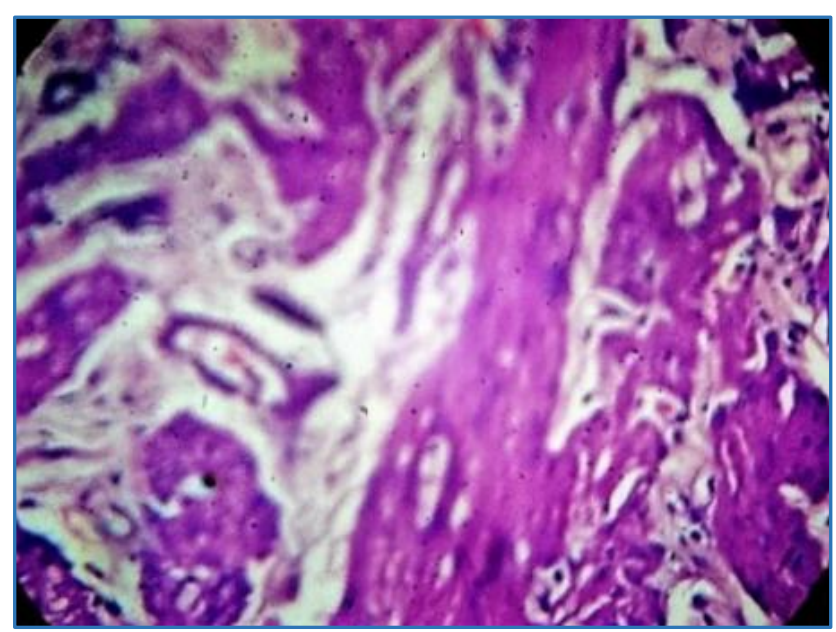

Fig. 14: Muscle Hypertrophy, H-Ex40

\section{DISCUSSION}

The histopathological findings observed in our study were comparable to that of Adriana Costa et al[5] and Amjad Almuslamani et al[6] as depicted in Table 1.
In our study, premalignant changes were identified in the background of chronic cholecystitis. So it may be presumed that histologic alterations like metaplasia and dysplasia may be the forerunners of the dreaded, carcinoma of gallbladder. Misra et al[7] have reported that due to occult evolution and nonspecific clinical features, gallbladder carcinoma is rarely diagnosed in early stage. So we advocate that cholecystectomy is the ideal treatment modality for cholelithiasis as subsequent histopathological examination of the resected specimens will allow the discovery of premalignant and early malignant changes. This will lead to significant decrease in the number of gallbladder malignancies diagnosed in advanced stages. That is why we are also of the opinion that histopathological study of all the resected specimens in routine cholecystectomies done for cholelithiasis is absolutely necessary.

\section{REFERENCES}

1. Munjal YP. API Textbook of Medicine. Jaypee Brothers Medical Pub 2012;9th edn:p 911.

2. Tandon RK. Prevalence and types of biliary stones in India. World J Gastroenterol 2000;6(Suppl 3):4-5.

3. Kasper, Fauci, Hauser, et al. Harrison's principle of internal medicine, 19th Edition. McGraw Hill Publication 2012;2:2076.

4. Stacey E Mills. Sternberg's diagnostic surgical pathology, $5^{\text {th }}$ Edition. Wolter Kluwer's 2010;2:1600-51.

5. Costa ALA, Bresciani CJC, Perez RO, et al. Are histological alterations observed in the gallbladder precancerous lesions? Clinical Science 2010;65(2):143-50.

6. Almuslamani AJ, Alsoude $\mathrm{M}$, Alomari $\mathrm{M}$, et al. Histopathological examination on suspicious gallbladder specimens at royal medical services hospital. Rawal Medical Journal 2011;36(2):93-6.

7. Misra S, Chaturvedi A, Misra NC, et al. Carcinoma of the gallbladder. Lancet Oncol 2003;4(3):167-76. 